\title{
The novel effects of 3,5,3'-triiodo-L-thyronine on myocyte contractile function and $\beta$-adrenergic responsiveness in dilated cardiomyopathy
}

Medical management of patients with chronic left ventricular dysfunction continues to be a difficult problem. Recent clinical and experimental studies have suggested that 3,5,3'-triiodo-L-thyronine improves left ventricular pump function. However, whether $3,5,3^{\prime}$-triiodo-L-thyronine directly improves myocyte contractile function in cardiomyopathic states is unknown. Accordingly, this study examined the direct effects of 3,5,3' -triiodo-L-thyronine on isolated myocyte contractile function in cardiocytes obtained from control $(n=6)$ pigs and pigs with tachycardia-induced dilated cardiomyopathy (atrial pacing at 240 beats/min for 3 weeks; $n=6$ ). Myocyte percent shortening and velocity of shortening were obtained at baseline and in the presence of 3,5,3'-triiodo-L-thyronine doses of 80 and 100 $\mathrm{pmol} / \mathrm{L}$. For both control and dilated cardiomyopathy groups, 3,5,3'-triiodo-L-thyronine caused a significant increase in myocyte contractile function. For example, a $100 \mathrm{pmol} / \mathrm{L}$ dose of $3,5,3^{\prime}$-triiodoL-thyronine increased myocyte velocity of shortening by $51 \%$ in control myocytes and by $54 \%$ in dilated cardiomyopathy myocytes compared with baseline. A second series of experiments was performed to determine whether $3,5,3^{\prime}$-triiodo-L-thyronine altered the responsiveness of the $\beta$-adrenergic receptor system in control and dilated cardiomyopathy myocytes. Myocyte contractile function was examined during $\beta$-adrenergic stimulation with isoproterenol alone and in myocytes preincubated with $3,5,3^{\prime}$-triiodo-L-thyronine doses of 80 and $100 \mathrm{pmol} / \mathrm{L}$ to which isoproterenol was added. Isoproterenol alone increased velocity of shortening by $139 \%$ in control and by $233 \%$ in dilated cardiomyopathy myocytes compared with baseline. This was significantly greater than the increase with $3,5,3^{\prime}$-triiodoL-thyronine alone. 3,5,3' -triiodo-L-thyronine followed by isoproterenol increased velocity of shortening by $245 \%$ in control and $313 \%$ in dilated cardiomyopathy myocytes compared with baseline. This was significantly greater than the response with $3,5,3^{\prime}$-triiodo-L-thyronine or isoproterenol alone and appeared to be greater than an additive response. The results from this study clearly demonstrated that 3,5,3'-triiodo-L-thyronine directly augmented myocyte contractile function in both control and dilated cardiomyopathy myocytes. In addition, 3,5,3'-triiodo-L-thyronine enhanced the contractile response to $\beta$-adrenergic stimulation in dilated cardiomyopathy. This study provides unique evidence to suggest that 3,5,3'-triiodo-L-thyronine may be a useful adjunct to conventional inotropic support in the setting of advanced left ventricular dysfunction. (J ThORaC CardovasC SURG 1994;108:672-9)

Jennifer D. Walker, MD, ${ }^{\mathrm{a}}$ Fred A. Crawford, MD, ${ }^{\mathrm{a}}$ Satoshi Kato, $\mathrm{MD},{ }^{\mathrm{b}}$ and

Francis G. Spinale, MD, PhD, ${ }^{\text {a }}$ Charleston, S.C.

From the Divisions of Cardiothoracic Surgery a and Adult Cardiology, ${ }^{b}$ Medical University of South Carolina, Charleston, S.C.

Supported by National Institutes of Health grant HL45024 (F.G.S.), Established Investigator Award of the American Heart Association (F.G.S.), and Nina S. Braunwald Research Fellowship of the Thoracic Surgery Foundation for Research and Education (J.D.W.).

Received for publication Feb. 28, 1994.

Accepted for publication April 18, 1994.

Address for reprints: Jennifer D. Walker, MD, Division of Cardiothoracic Surgery, Medical University of South Carolina, 171 Ashley Ave., Charleston, SC 29425.
$\mathrm{P}$ tricular (LV) dysfunction continues to be a difficult problem both in the setting of chronic congestive heart failure and myocardial ischemia, as well as after cardiac operations. Inotropic agents used to improve contractile function include digitalis, $\beta$-adrenergic receptor agonists, and phosphodiesterase inhibitors. However, the inotropic

Copyright 1994 by Mosby-Year Book, Inc. $0022-5223 / 94 \$ 3.00+0 \quad \mathbf{1 2} / \mathbf{1} / \mathbf{5 7 1 7 1}$ 
effectiveness of these agents appears diminished in patients with chronic LV dysfunction. ${ }^{1}$ These limitations may result from the fact that these inotropic agents depend on intact sarcolemmal receptor transduction systems to exert their positive inotropic effects. However, chronic LV dysfunction as seen in cardiomyopathic disease is associated with alterations in sarcolemmal receptor systems and therefore may reduce the effectiveness of these agents. ${ }^{2}$ For example, patients with chronic LV dysfunction exhibit changes in the myocardial sarcolemmal $\beta$-adrenergic receptor system. ${ }^{1-4}$ Specifically, Bristow $^{2}$ reported down regulation of $\beta$-adrenergic receptors, as well as alterations in adenylate cyclase activation, in patients with dilated cardiomyopathy (DCM). These alterations in the $\beta$-adrenergic receptor system in patients with chronic LV dysfunction result in depressed responsiveness to administration of $\beta$-adrenergic agonists. ${ }^{1}$ Because $\beta$-adrenergic agonists are commonly used clinically to augment depressed LV performance, particularly after cardiopulmonary bypass, this diminished responsiveness is clinically important. Recent studies suggest that $T_{3}$, whichmayexertitseffectsindependentof sarcolemmal receptor systems, may acutely alter $\beta$-adrenergic responsiveness, may augment $\mathrm{LV}$ contractile function, and may provide a unique mode of inotropic therapy in patients with chronic LV dysfunction. Recent clinical and experimental studies have suggested that acute administration of 3,5,3'-triiodo-1-thyronine $\left(\mathrm{T}_{3}\right)$ improves $\mathrm{LV}$ pump performance in the setting of LV dysfunction. ${ }^{5-9}$ For example, Morkin and associates ${ }^{10}$ reported that treatment with thyroid hormone for 3 days in a postinfarction model in rats produced a positive inotropic response. In addition, Hammond and coworkers ${ }^{11}$ reported myocardial $\beta$-adrenergic receptor up regulation and increased adrenergic sensitivity in pigs given short-term $\mathrm{T}_{3}$ treatment. However, it remains unclear whether $T_{3}$ acts directly on the myocyte, whether $T_{3}$ acts independently of or synergistically on the $\beta$-adrenergic receptor system in tachycardia-induced DCM, and the extent to which $\mathrm{T}_{3}$ augments contractile function in DCM. Therefore, the overall goal of the present study was to examine the direct effects of acute administration of $\mathbf{T}_{3}$ on isolated myocyte contractile function in a model of DCM.

\section{Methods}

Twelve weight-matched pigs (Yorkshire strain, $28 \mathrm{~kg}$ ) were randomly assigned to one of two groups: (1) pigs subjected to supraventricular pacing tachycardia at 240 beats/min for 3 weeks $(n=6)$ and (2) sham-operated control pigs $(n=6)$. The pacing protocol was performed as previously described. ${ }^{12,13}$ In brief, a stimulating electrode was sutured onto the left atrium and pacemakers were implanted and modified for programming heart rates up to 400 beats/min (Spectrax, Medtronic, Inc., Minneapolis, Minn.). Seven to 10 days after recovery from the surgical procedure, atrial pacing at 240 beats/min was initiated. Electrocardiograms were obtained frequently during the pacing protocol to ensure the presence of $1: 1$ conduction. The sham-operated control pigs were cared for in identical fashion with the exception of the pacing protocol. All animals were treated and cared for in accordance with the National Institutes of Health Guide for the Care and Use of Laboratory Animals. ${ }^{14}$

On the day of study, the animals were sedated with $10 \mathrm{mg}$ of midazolam (Versed, Hoffman-La Roche, Inc., Nutley, N.J.), were placed in a custom-designed sling that allowed the animal to rest comfortably, an electrocardiogram was established, and the pacemaker was deactivated (pacing group only). Twodimensional and M-mode echocardiographic studies (ATL Ultramark VI, $2.25 \mathrm{MHz}$ transducer, Bothell, Wash.) were used to image the LV from a right parasternal approach Echocardiographic measurements were performed as previously described. ${ }^{12,13,15} \mathrm{Next}$, the animals were anesthetized with isoflurane $(0.5 \% / 1.5 \mathrm{~L} / \mathrm{min})$, and their lungs were ventilated through a nonrecirculating anesthesia circuit. A sternotomy was then performed, and the heart was quickly extirpated and placed in an oxygenated Krebs solution. The LV and septum were quickly weighed. The region of the $\mathrm{LV}$ free wall comprising the left circumflex coronary artery was dissected free, the artery cannulated, and the tissue prepared for myocyte isolation.

Myocyte isolation and contractile function measurement. By means of methods described by this laboratory previously, ${ }^{16,17}$ oxygenated modified Krebs solution containing aerobic substrates and collagenase $(0.5 \mathrm{mg} / \mathrm{ml}$, type $\mathrm{II} ; 146 \mathrm{U} / \mathrm{mg}$, Worthington, $\mathrm{Pa}$.) was perfused and recirculated through the cannulated circumflex artery for 20 minutes. The tissue was then minced into $2 \mathrm{~mm}$ sections and added to an oxygenated trituration solution containing calcium chloride $400 \mu \mathrm{mol} / \mathrm{L}$ and collagenase $(0.5 \mathrm{mg} / \mathrm{ml})$. The tissue and trituration solution were transferred to a centrifuge tube and gently agitated. At 15-minute intervals, the supernatant was removed and filtered and the cells were allowed to settle. The myocyte pellet was then resuspended in standard culture media (media 199: Nutrient Mixture F-12, $\mathrm{Ca}^{2+} 2 \mathrm{mmol} / \mathrm{L}$, Gibco Laboratories, Grand Island, N.Y.).

Isolated myocytes were placed in a thermostatically controlled chamber $\left(37^{\circ} \mathrm{C}\right)$ fitted with a coverslip on the bottom for imaging on an inverted microscope (Axiovert IM35, Zeiss Inc., Oberkochen, Germany). The volume of the chamber was $2.5 \mathrm{ml}$ and contained two stimulating platinum electrodes. The myocytes were imaged with a $20 \times$ long-working-distance Hoffmann Modulation Contrast objective (Modulation Optics Inc., Greenvale, N.Y.). Myocyte contractions were elicited by field stimulating the tissue chamber at $1 \mathrm{~Hz}$ (S11, Grass Instruments, Quincy, Mass.) and imaged with a charge-coupled device with noninterlaced scan rate of $240 \mathrm{~Hz}$ (GPCD60, Panasonic, Secaucus, N.J.). Myocyte motion signals were captured with the cell parallel to the video raster lines, and this video signal was input through an edge detector system (Crescent Electronics, Sandy, Utah). The distance between the left and right myocyte edges were converted into a voltage signal, digitized, and input to a computer (80286;ZBV2526, Zenith Data Systems, St. Joseph, Mich.) for subsequent analysis. Stimulated myocytes were allowed a 5 -minute stabilization period after which contraction data for each myocyte were recorded from a minimum of 20 consecutive contractions. Parameters comput- 
Table I. Left ventricular function after chronic supraventricular tachycardia

\begin{tabular}{lcc} 
& Control & $D C M$ \\
\hline $\begin{array}{l}\text { LV weight/body weight } \\
\text { (gm/kg) }\end{array}$ & $3.0 \pm 0.2$ & $3.1 \pm 0.4$ \\
Intrinsic heart rate & & \\
$\quad$ (beats/min) & $109 \pm 6$ & $153 \pm 8^{*}$ \\
End-diastolic dimension (cm) & $3.4 \pm 0.2$ & $5.1 \pm 0.3^{*}$ \\
Fractional shortening (\%) & $30 \pm 2$ & $10 \pm 3^{*}$ \\
Sample size $(n)$ & 6 & 6 \\
\hline
\end{tabular}

$\overline{D C M}$, Dilated cardiomyopathy after 3 weeks of supraventricular tachycardia ( 240 beats $/ \mathrm{min}$ ).

${ }^{*} p<0.05$ versus control.

ed from the digitized contraction profiles included percentage shortening, peak velocity of shortening peak velocity of lengthening total contraction duration, and time to peak contraction.

Experimental design. Myocytes from each control and paced pig were randomly assigned to the following treatment groups: (1) a $\mathrm{T}_{3}$ dose of $80 \mathrm{pmol} / \mathrm{L}$ (Sigma Chemical Company, St. Louis, Mo.), (2) a $T_{3}$ dose of $100 \mathrm{pmol} / \mathrm{L}$, and (3) an isoproterenol dose of $25 \mathrm{nmol} / \mathrm{L}$. This concentration of isoproterenol has been reported previously to be the maximum effective dose for this myocyte preparation. ${ }^{16,17}$ Additional groups included (4) a $T_{3}$ dose of $80 \mathrm{pmol} / \mathrm{L}$ followed by an isoproterenol dose of $25 \mathrm{nmol} / \mathrm{L}$ and (5) a $\mathrm{T}_{3}$ dose of $100 \mathrm{pmol} / \mathrm{L}$ followed by an isoproterenol dose of $25 \mathrm{nmol} / \mathrm{L}$. Baseline measurements were obtained for each cell before the addition of either $T_{3}$ or isoproterenol. Preliminary studies conducted by this laboratory using increasing concentrations of $\mathrm{T}_{3}(0.01$ to $0.5 \mathrm{nmol} / \mathrm{L})$ were performed to generate a dose-response curve. From these doseresponse measurements, the effective concentration of $\mathrm{T}_{3}$ for a $50 \%$ response was computed to be $80 \mathrm{pmol} / \mathrm{L}$, and the effective concentration for a $100 \%$ response was computed to be 100 $\mathrm{pmol} / \mathrm{L}$. These concentrations of $T_{3}$ were used throughout the present study. A minimum of 4 cells were assigned to each treatment group for each pig.

Data analysis. LV function was compared between the two groups by means of Student's $t$ test (Table I). The steady-state myocyte function was analyzed at baseline and after treatment with $T_{3}$, isoproterenol, or both $T_{3}$ and isoproterenol by analysis of variance. If the analysis of variance revealed significant differences, pairwise mean differences were compared by means of Bonferroni-adjusted significance levels. ${ }^{18}$ To determine whether $\mathrm{T}_{3}$ had a synergistic effect on $\beta$-adrenergic responsiveness with isoproterenol, we examined the interactive effects of $T_{3}$ and isoproterenol by means of analysis of variance with a fixed-effects model. All statistical procedures were performed with the use of the BMDP statistical software package (BMDP Statistical Software Inc., Los Angeles, Calif.). Results are presented as mean \pm standard error of the mean. Values of $p<0.05$ were considered to be statistically significant.

\section{Results}

LV function with pacing-induced cardiomyopathy. All of the pigs subjected to 3 weeks of pacing-induced supraventricular tachycardia survived the pacing protocol and were found to have symptoms of dyspnea and
Table II. Effects of $T_{3}$ on myocyte function

\begin{tabular}{|c|c|c|c|}
\hline & \multicolumn{3}{|c|}{$T_{3}, 80 \mathrm{pmol} / \mathrm{L}$} \\
\hline & Baseline & $80 \mathrm{pMT}_{3}$ & $T_{3}, 100 \mathrm{pmol} / \mathrm{L}$ \\
\hline \multicolumn{4}{|c|}{ Percent shortening $(\%)$} \\
\hline Control & $4.6 \pm 0.1$ & $6.2 \pm 0.2 \dagger$ & $6.4 \pm 0.2 \dagger$ \\
\hline $\mathrm{DCM}$ & $2.2 \pm 0.1^{*}$ & $2.7 \pm 0.1^{*}$ & $3.1 \pm 0.2^{*}$ \\
\hline \multicolumn{4}{|c|}{ Shortening velocity $(\mu \mathrm{m} / \mathrm{sec})$} \\
\hline Control & $45.1 \pm 1.5$ & $61.3 \pm 2.7 \dagger$ & $73.5 \pm 3.2 \dagger$ \\
\hline DCM & $29.2 \pm 1.3^{*}$ & $43.7 \pm 3.3^{* \dagger}$ & $42.3 \pm 3.6 * \dagger$ \\
\hline \multicolumn{4}{|c|}{ Lengthening velocity $(\mu \mathrm{m} / \mathrm{sec})$} \\
\hline Control & $50.8 \pm 1.9$ & $72.1 \pm 3.3 \dagger$ & $80.4 \pm 3.2 \dagger$ \\
\hline DCM & $28.9 \pm 1.5^{*}$ & $40.8 \pm 3.8^{*}$ & $46.1 \pm 3.7 * \dagger$ \\
\hline \multicolumn{4}{|c|}{ Time to peak contraction (msec) } \\
\hline Control & $285.1 \pm 6.5$ & $309.4 \pm 9.8$ & $300.6 \pm 11.9$ \\
\hline DCM & $256.0 \pm 7.3^{*}$ & $229.0 \pm 12.4^{*}$ & $262.2 \pm 14.9^{*}$ \\
\hline \multicolumn{4}{|c|}{ Duration of contraction (msec) } \\
\hline Control & $530.4 \pm 9.0$ & $553.6 \pm 18.2$ & $527.6 \pm 19.4$ \\
\hline DCM & $493.4 \pm 15.8$ & $466.4 \pm 32.0$ & $489.3 \pm 27.8$ \\
\hline
\end{tabular}

All values are presented as mean \pm standard error of the mean. $T_{3}, 3,5,3^{\prime}$-Triiodo-L-thyronine; $D C M$, dilated cardiomyopathy after 3 weeks of pacing at 240 beats/min.

${ }^{*} p<0.05$ versus control.

$\dagger p<0.05$ versus baseline.

tachypnea at terminal study. An LV echocardiographic study was performed on each pig at terminal study with results summarized in Table I. Chronic pacing-induced supraventricular tachycardia caused LV dilatation and dysfunction consistent with results previously reported by this laboratory. ${ }^{12,13,19}$ At autopsy, the pigs subjected to pacing exhibited bilateral pleural effusions and ascites. Thus, consistent with previous reports from this laboratory, ${ }^{12,13,19}$ chronic pacing-induced tachycardia caused clinical and functional manifestations of a DCM. These pigs will be referred to as the DCM group.

Steady-state myocyte contractile function. A high yield ( $>70 \%$ ) of viable (rod shaped; quiescent in culture) myocytes was isolated from each control pig and each pig with tachycardia-induced DCM used in this study. Nonstimulated, resting length for control myocytes was $139.1 \pm 1.9 \mu \mathrm{m}$ and for DCM myocytes was $184.4 \pm 3.8$ $\mu \mathrm{m}(p<0.05)$. This increase in isolated myocyte length is consistent with past reports in this model of DCM. ${ }^{12,13}$ Baseline steady-state measurements of isolated myocyte contractile function in the control group and in the group with DCM are summarized in Table II. A significant depression in baseline indices of myocyte contractile function was observed in DCM myocytes as compared with controls, consistent with previous studies. ${ }^{12}$ For example, baseline myocyte percent shortening was $52 \%$ lower and velocity of shortening was 35\% lower in DCM myocytes than in controls. Thus, as previously reported, DCM myocytes exhibited significant abnormalities in basal steady-state contractile function. ${ }^{12,19}$ 


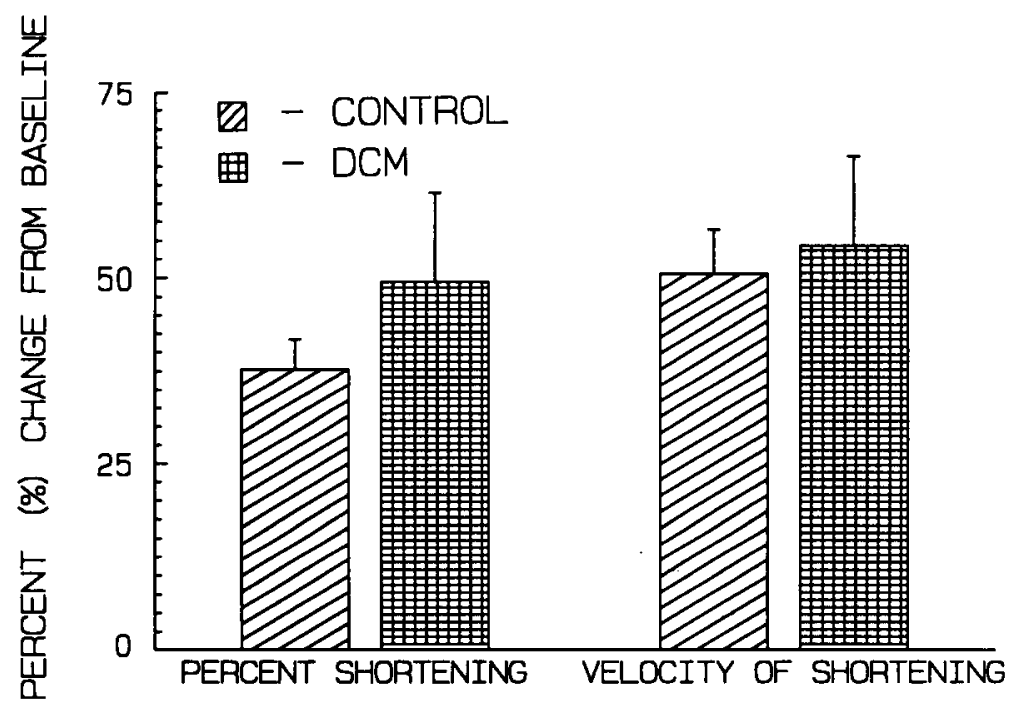

Fig. 1. Effect of $T_{3} 100 \mathrm{pmol} / \mathrm{L}$ on the percent and velocity of myocyte shortening for control and DCM myocytes. Data are expressed as percent change from baseline. $T_{3}$ caused an equivalent increase in myocyte percent and velocity of shortening in both control and DCM myocytes.

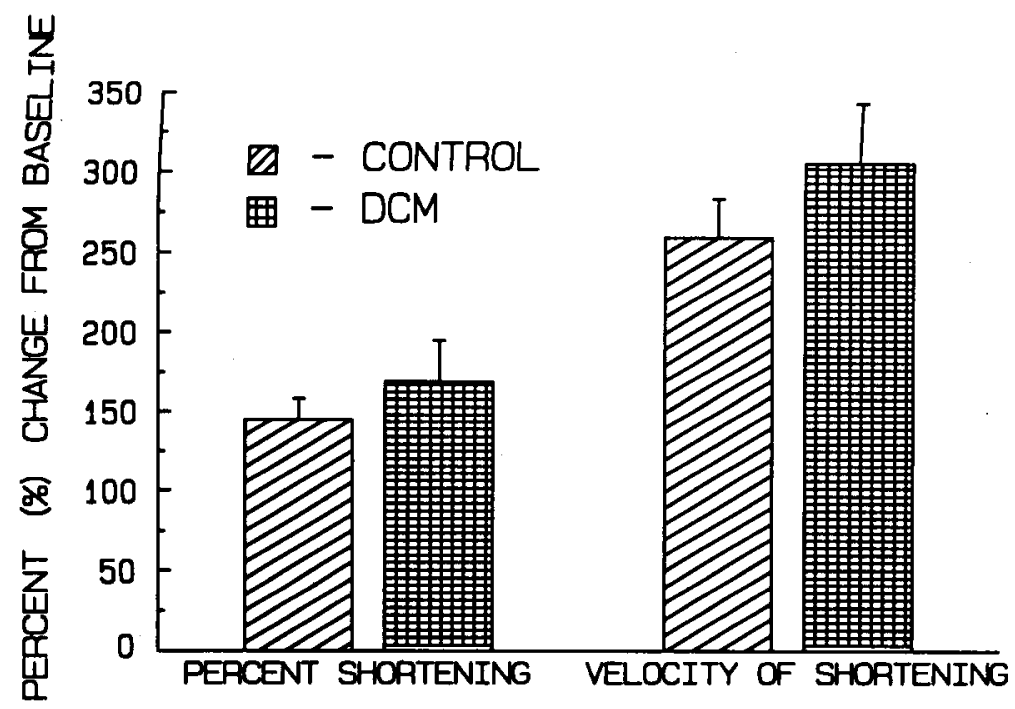

Fig. 2. Effect of $T_{3}$ and isoproterenol on myocyte percent and velocity of shortening for both control and DCM myocytes. Data are expressed as percent change from baseline. $T_{3}$ and isoproterenol caused an equivalent increase in percent and velocity of myocyte shortening in both control and DCM myocytes. Note that the scale for the y axis differs for the two figures.

Myocyte contractile function with $\mathbf{T}_{\mathbf{3}}$. With the short-term addition of $T_{3}$ in concentrations of either 80 or $100 \mathrm{pmol} / \mathrm{L}$, indices of myocyte contractile function significantly increased from baseline values for both control and DCM myocytes (see Table II). For example, in control myocytes, a 100 pmol concentration of $T_{3}$ increased myocyte percent shortening by $38 \%$ and increased veloc- ity of shortening by $51 \%$. In DCM myocytes, similar directional changes in myocyte contractile function occurred. In the presence of $T_{3}$, myocyte contractile function in DCM remained lower than contractile function in control myocytes treated with the same dose of $T_{3}$. However, the percent increase in contractile function caused by $T_{3}$ was equivalent in DCM and control myo- 
Table III. The effects of isoproterenol and $T_{3}$ on myocyte function

\begin{tabular}{|c|c|c|c|c|}
\hline & Baseline & $\begin{array}{c}\text { Isoproterenol } \\
(25 \mathrm{nmol} / \mathrm{L})\end{array}$ & $\begin{array}{c}\text { Isoproterenol } \\
\begin{array}{c}(25 \mathrm{nmol} / \mathrm{L}) \\
+T_{3}\end{array} \\
(80 \mathrm{pmol} / \mathrm{L})\end{array}$ & $\begin{array}{c}\text { Isoproterenol } \\
\begin{array}{c}(25 \mathrm{nmol} / \mathrm{L}) \\
+T_{3}\end{array} \\
(100 \mathrm{pmol} / \mathrm{L})\end{array}$ \\
\hline \multicolumn{5}{|c|}{ Percent shortening (\%) } \\
\hline Control & $4.5 \pm 0.1$ & $8.8 \pm 0.6 \dagger$ & $11.4 \pm 0.5+\neq$ & $12.2 \pm 0.5+\ddagger$ \\
\hline DCM & $2.1 \pm 0.1^{*}$ & $4.7 \pm 0.5^{* \dagger}$ & $6.2 \pm 0.5^{*} \dagger \ddagger$ & $5.8 \pm 0.6^{* \dagger}$ \\
\hline \multicolumn{5}{|c|}{ Shortening velocity $(\mu \mathrm{m})$} \\
\hline Control & $45.0 \pm 1.3$ & $100.5 \pm 7.2 \dagger$ & $162.1 \pm 8.9+t$ & $166.3 \pm 7.4 \dagger+$ \\
\hline DCM & $28.8 \pm 1.3^{*}$ & $74.3 \pm 8.4^{* \dagger}$ & $151.6 \pm 13.5+\ddagger$ & $117.1 \pm 13.2^{*} \dagger \ddagger$ \\
\hline \multicolumn{5}{|c|}{ Lengthening velocity $(\mu \mathrm{m})$} \\
\hline Control & $50.2 \pm 1.7$ & $90.9 \pm 6.5 \dagger$ & $157.2 \pm 11.2 \dagger \ddagger$ & $162.4 \pm 10.4 t \neq$ \\
\hline DCM & $27.6 \pm 1.3^{*}$ & $56.1 \pm 7.8^{*} \dagger$ & $122.4 \pm 18.0^{* \dagger \ddagger}$ & $100.3 \pm 14.9^{*} \dagger \ddagger$ \\
\hline \multicolumn{5}{|c|}{ Time to peak contraction (msec) } \\
\hline Control & $285.6 \pm 6.1$ & $232.1 \pm 11.2 \dagger$ & $218.9 \pm 8.3 \dagger$ & $241.8 \pm 14.2 \dagger$ \\
\hline DCM & $257.0 \pm 6.4^{*}$ & $218.9 \pm 12.1 \dagger$ & $162.1 \pm 7.5 \dagger$ & $175.3 \pm 8.6^{* \dagger}$ \\
\hline \multicolumn{5}{|c|}{ Duration of contraction (msec) } \\
\hline Control & $532.0 \pm 8.5$ & $511.2 \pm 23.1$ & $465.8 \pm 25.9 \dagger$ & $474.3 \pm 24.4 \dagger$ \\
\hline DCM & $498.1 \pm 13.1$ & $500.9 \pm 30.0$ & $393.4 \pm 21.5$ & $415.0 \pm 20.9 \dagger$ \\
\hline
\end{tabular}

All values presented as mean \pm standard error of the mean. $T_{3}, 3,5,3^{\prime}$-Triodo-L-thyronine; $D C M$, dilated cardiomyopathy after 3 weeks of pacing at 240 beats/ $\min$.

${ }^{*} p<0.05$ versus control.

$\dagger p<0.05$ versus baseline.

$\ddagger p<0.05$ versus isoproterenol alone.

cytes (Fig. 1). Thus acute administration of $T_{3}$ improved indices of myocyte contractile function in both control and DCM myocytes. Furthermore, the percent increase produced by $\mathrm{T}_{3}$ is comparable between control and DCM myocytes.

Myocyte contractile function with $T_{3}$ and $\beta$-adrenergic responsiveness. Isoproterenol increased myocyte contractile function in both control and DCM myocytes, as in previous studies (Table III). ${ }^{16}$ Isoproterenol increased myocyte velocity of shortening by $139 \%$ in control myocytes and by $233 \%$ in DCM myocytes over baseline values (Fig. 2). However, the absolute values for percent and velocity of shortening remained significantly below control values. Diminished $\beta$-adrenergic responsiveness with development of DCM is consistent with previous reports from this laboratory and others. ${ }^{1-4,20}$

Incubation with $T_{3}$ followed by the addition of isoproterenol significantly increased indices of myocyte contractile function to a greater extent than isoproterenol alone or $\mathrm{T}_{3}$ alone for both control and DCM myocytes. For example, in control myocytes preincubation with a $100 \mathrm{pmol} / \mathrm{L}$ dose of $T_{3}$ followed by the addition of isoproterenol increased velocity of shortening by $246 \%$ above baseline values (see Table III). Similarly, DCM myocytes incubated with $T_{3} 100 \mathrm{pmol} / \mathrm{L}$ followed by isoproterenol exhibited a $368 \%$ increase in velocity of shortening over baseline values. Thus short-term administration of $\mathrm{T}_{3}$ followed by $\beta$-adrenergic receptor stimulation caused increased myocyte contractile function in both control and DCM myocytes that was greater than that seen with either agent $\left(\mathrm{T}_{3}\right.$ or isoproterenol) alone.

Analysis of variance was performed to determine whether the results obtained with the addition of $T_{3}$ followed by isoproterenol were due to additive effects, synergistic effects, or both. This analysis revealed that (1) $T_{3}$ significantly affected myocyte contractile function in both control and DCM myocytes and (2) $T_{3}$ administration followed by $\beta$-adrenergic receptor stimulation significantly enhanced myocyte contractile function over and above isoproterenol alone and $\mathrm{T}_{3}$ alone. Furthermore, the analysis revealed a significant interaction between administration of $T_{3}$ followed by isoproterenol and the treatment groups, that is, control versus $D C M$ ( $F$ value $=2.64$; $p=0.02$ ). That is, the effects of $T_{3}$ followed by isoproterenol were significantly different in the DCM group than in the control group. In the control group, $T_{3}$ exerted its influence independent of the $\beta$-adrenergic receptor system. In DCM myocytes, $\mathrm{T}_{3}$ was synergistic with the $\beta$-adrenergic receptor system such that $\beta$-adrenergic responsiveness to isoproterenol significantly increased in more than an additive manner.

\section{Discussion}

The purpose of this study was to examine the direct effects of acute $T_{3}$ administration on isolated myocyte contractile function in a model of DCM induced by 
supraventricular tachycardia. This study demonstrated that the acute administration of $\mathrm{T}_{3}(1)$ increased isolated myocyte contractile function, (2) increased $\beta$-adrenergic responsiveness in both control and DCM myocytes, and (3) selectively enhanced $\beta$-adrenergic responsiveness in DCM myocytes. Results from the present study suggest that acute administration of $T_{3}$ may provide a unique method of increasing contractile function in the setting of chronic LV dysfunction.

Historically, the effects of thyroid hormone $\left(T_{3}\right)$ on LV function have generally been thought to require modulation of contractile protein synthesis through binding of intranuclear receptors. ${ }^{21}$ These alterations in protein synthesis, however, clearly do not explain the mechanism for the short-term effects of $T_{3}$ on myocyte contractile function. In the present study, myocyte contractile performance increased within 30 seconds of $T_{3}$ administration. Thus an alternative mechanism for the short-term effects of $T_{3}$ other than intranuclear binding must be operative. Dudley and Baumgarten ${ }^{22}$ recently demonstrated that increased bursting of sodium channels in isolated rabbit myocytes occurred within 30 seconds of acute administration of $T_{3}$ to the extracellular face of the sarcolemma. Thus $T_{3}$ may acutely increase intracellular sodium and exert a positive inotropic effect via the $\mathrm{Na}^{+} /$ $\mathrm{Ca}^{2+}$ exchanger. Rudinger and associates ${ }^{23}$ reported an acute increase in $\mathrm{Ca}^{2+}$ adenosinetriphosphatase activity in rabbit sarcolemmal preparations in the presence of thyroid hormone. Chang and Kunos ${ }^{24}$ reported that acute administration of $T_{3}$ to rat myocardium caused a significant increase in the $\beta$-adrenergic receptor density. The present study demonstrated that $T_{3}$ acutely augmented $\beta$-adrenergic responsiveness in isolated cardiomyopathic myocytes. Thus a potential mechanism for the enhanced $\beta$-adrenergic responsiveness of DCM myocytes to acute administration of $T_{3}$ may be an increase in $\beta$-adrenergic receptor density. On the basis of the results of the present study, future studies that examine the short-term effects of $T_{3}$ on basic myocyte contractile properties and receptor systems may be appropriate.

Clinical reports have documented that patients with chronic LV dysfunction exhibit depressed levels of the active form of thyroid hormone, $T_{3},{ }^{5,6,25-27}$ Specifically, Hamilton and colleagues ${ }^{25}$ reported an association between a depressed level of $T_{3}$ and indices of $L V$ function. In a second report, Hamilton ${ }^{26}$ presented evidence suggesting a relationship between decreased levels of $T_{3}$ and survival rates in patients with LV dysfunction. Buccino and coworkers ${ }^{28}$ reported that the maximum velocity of isotonic shortening in feline papillary muscles varied directly with the thyroid state. Thus past clinical and experimental studies have suggested that $T_{3}$ appears to be an important determinant in overall LV performance. ${ }^{25-27}$ The present study demonstrated that acute administration of $T_{3}$ increased indices of myocyte contractile function in the control state and with the development of DCM. Results from the present study provide direct evidence for the contributory role of $T_{3}$ in the modulation of contractile function.

Novitzky and associates ${ }^{8}$ reported that acute administration of $\mathrm{T}_{3}$ led to hemodynamic improvement and reduced need for inotropic support in patients with LV dysfunction after cardiopulmonary bypass. In an experimental study, these same investigators also observed improved cardiac output in dogs subjected to 15 minutes of myocardial ischemia followed by the acute administration of $T_{3} .{ }^{5,8,29}$ Morkin and colleagues ${ }^{10}$ reported increased rate of rise of $L V$ pressure after 3 days of thyroxine administration in rats with chronic $L V$ dysfunction produced by coronary artery ligation. These past clinical and experimental studies suggested that $T_{3}$ had beneficial effects when administered acutely in the setting of acute LV dysfunction or for longer periods (3 days) in rats with chronic LV dysfunction. However, no study has directly examined the effects of the acute administration of $T_{3}$ on isolated myocyte contractile performance in the setting of cardiomyopathic disease. The present study, for the first time, directly demonstrated that acute administration of $\mathrm{T}_{3}$ improved indices of isolated myocyte contractile function after the development of DCM.

$\beta$-Adrenergic receptor agonists are commonly used as inotropic agents in the setting of LV dysfunction. The effects of these agonists are dependent on intact sarcolemmal receptor transduction systems. However, Bristow ${ }^{2}$ has reported down regulation and uncoupling of the $\beta$-adrenergic receptor system in patients with chronic LV dysfunction. This laboratory and others have reported that DCM is associated with similar alterations in the $\beta$-adrenergic receptor system. ${ }^{30-32}$ Specifically, pacinginduced DCM in swine or dogs caused a $25 \%$ to $57 \%$ decrease in total $\beta$-adrenergic receptor density. ${ }^{1,30,32}$ The past reports in this model of pacing-induced DCM also show decreased $\beta$-adrenergic responsiveness. ${ }^{1,30,32}$ These changes in the $\beta$-adrenergic receptor density and $\beta$-adrenergic responsiveness with pacing-induced DCM are similar to those that have been observed in patients with chronic LV dysfunction. ${ }^{2-4,20}$ Results from the present study demonstrated that $\beta$-adrenergic responsiveness was decreased in the DCM myocytes consistent with these past reports. ${ }^{30-32}$ Hammond, ${ }^{11}$ Williams, ${ }^{33}$ Bilezikian $^{34}$ and others have suggested that a relationship exists between administration of $\mathrm{T}_{3}$, or the thyroid state, and the $\beta$-adrenergic receptor system. More recently, acute administration of $T_{3}$ has been shown to acutely alter the 
number of cardiac $\beta$-adrenergic receptors. ${ }^{24}$ The present study therefore examined myocyte contractile function with the concomitant administration of $\mathrm{T}_{3}$ and $\mathrm{a} \beta$-adrenergic receptor agonist in this model of DCM. Results from the present study demonstrated that acute administration of $T_{3}$ increased $\beta$-adrenergic responsiveness in DCM myocytes. Thus these results suggest that acute administration of $T_{3}$ may have a beneficial interaction with $\beta$-adrenergic agonists in the setting of cardiomyopathic disease.

Previous experimental studies have examined the ability of various inotropic agents to improve contractile function in this model of DCM. ${ }^{12,35}$ Specifically, this laboratory has demonstrated that the responsiveness of DCM myocytes to increased extracellular $\mathrm{Ca}^{2+}$ was significantly blunted. ${ }^{12}$ Furthermore, this laboratory reported a reduction in cardiac glycoside receptor density and decreased responsiveness to the positive inotropic effects of the glycoside ouabain. ${ }^{35}$ Finally, previous studies, as well as the present study, have demonstrated blunted $\beta$-adrenergic responsiveness with DCM. ${ }^{1,30,32}$ Unlike these past reports, however, the present study clearly demonstrated that the concomitant administration of $\mathrm{T}_{3}$ and the $\beta$-adrenergic receptor agonist isoproterenol exhibited a synergistic effect on myocyte contractile function in DCM myocytes. Thus, for the first time, an inotropic regimen has been demonstrated to improve myocyte contractile function with tachycardia-induced DCM.

Significant differences exist between this in vitro model and the effects of $T_{3}$ given either acutely or chronically in vivo. First, $T_{3}$ has multiple systemic effects in vivo such as induction of catecholamine release and alteration of heart rate. The present study examined the effects of $T_{3}$ on myocyte contractile function in vitro, in an environment independent of these extracellular influences. Thus any secondary effects of $T_{3}$ on isolated myocyte contractile function could not be determined from the present study design. Second, complete delivery of $T_{3}$ to the myocyte was achieved in the present study, which may not be the case in vivo. Finally, this study examined the acute effects of $T_{3}$ on myocyte contractile performance with a single dose, but did not address the effects of repetitive or chronic administration. On the basis of the results of the present study, which demonstrated that acute administration of $\mathrm{T}_{3}$ increased isolated myocyte contractile performance in both control and DCM myocytes, further studies are warranted to examine the effects of $T_{3}$ in vivo, with chronic dosing and with different dosing regimens.

Congestive heart failure remains a major cause of morbidity and mortality in patients with advanced left ventricular dysfunction. Because of the complexity in- volved in the management of these patients, alternative pharmacologic therapy continues to be investigated. Recent clinical and experimental reports have documented improved indices of $\mathrm{LV}$ function after $\mathrm{T}_{3}$ administration in vivo. ${ }^{5,8}$ The present study, however, demonstrated for the first time that acute administration of $\mathrm{T}_{3}$ exerted a positive effect on myocyte contractile function in a model of cardiomyopathic disease. In addition, the present study provided evidence that $T_{3}$ acutely influenced the $\beta$-adrenergic receptor system, thus improving the responsiveness of these cardiomyopathic myocytes to $\beta$-adrenergic receptor stimulation. Results from this study suggest that continued investigation of the possibility that acute administration of $T_{3}$ may be a useful therapeutic adjunct in the treatment of patients with LV dysfunction is warranted.

\section{REFER EN CES}

1. Tanaka R, Fulbright BM, Mukherjee R, et al. The cellular basis for the blunted response to $\beta$-adrenergic stimulation in supraventricular tachycardia-induced cardiomyopathy. J Mol Cell Cardiol 1993;25:101-19.

2. Bristow MR. Changes in myocardial and vascular receptors in heart failure. J Am Coll Cardiol 1993;22(Suppl):I21321.

3. Bristow MR, Ginsburg R, Umans V, et al. $\beta 1$ and $\beta 2$ Adrenergic-receptor subpopulations in nonfailing and failing human ventricular myocardium: coupling of both receptor subtypes to muscle contraction and selective $\beta 1$-receptor down regulation in heart failure. Circ Res 1986;59:297-309.

4. Fowler MB, Laser JA, Hopkins GL, Minobe W, Bristow MR. Assessment of the $\beta$-adrenergic receptor pathways in the intact failing human heart: progressive receptor downregulation and subsensitivity to agonist response. Circulation 1986;74:1290-302.

5. Novitzky D, Human PA, Cooper DK. Inotropic effect of triiodothyronine following myocardial ischemia and cardiopulmonary bypass: an experimental study in pigs. Ann Thorac Surg 1988;45:50-5.

6. Holland FW, Brown PS, Clark RE. Acute severe postischemic myocardial depression reversed by triiodothyronine Ann Thorac Surg 1992;54:301-5.

7. Dyke CM, Yeh T, Lehman JD, et al. Triiodothyronine-enhanced left ventricular function after ischemic injury. Ann Thorac Surg 1991;52:14-9.

8. Novitzky D, Cooper DK, Barton CI, et al. Triiodothyronine as an inotropic agent after open heart surgery. J THORAC Cardiovasc Surg 1989;98:972-8.

9. Wechsler AS, Kadletz M, Ding M, Abd-Elfattah A, Dyke C. Effects of triiodothyronine on stunned myocardium. J Card Surg 1993;8(suppl):338-41.

10. Morkin E, Pennock GD, Raya TE, Bahl JJ, Goldman S. Studies on the use of thyroid hormone and a thyroid hor- 
mone analogue in the treatment of congestive heart failure. Ann Thorac Surg 1993;56:S54-60.

11. Hammond HK, White FC, Buxton ILO, Saltzstein P, Brunton LL, Longhurst JC. Increased myocardial beta-receptors and adrenergic responses in hyperthyroid pigs. Am J Physiol 1987;252:H283-90.

12. Spinale FG, Fulbright BM, Mukherjee R, et al. Relationship between ventricular and myocyte function with tachycardia induced cardiomyopathy. Circ Res 1992;71:174-87.

13. Spinale FG, Zellner JL, Tomita M, Crawford FA, Zile MR. Relationship between ventricular and myocyte remodeling with the development and regression of supraventricular tachycardia induced cardiomyopathy. Circ Res 1991;69:1058-67.

14. Committee on the care and use of laboratory animals. Guide for the care and use of laboratory animals. Washington, DC: National Research Council, Institute of Laboratory Animal Resources, 1985 (NIH Publication No. 86-23).

15. Sahn DJ, DeMaria A, Kisslo J, Weyman A. Recommendations regarding quantitation in M-mode echocardiography: results of a survey of echocardiographic measurements. Circulation 1978;58:1072-83.

16. Spinale FG, Mukherjee R, Fulbright BM, Hu J, Crawford FA, Zile MR. Contractile properties of isolated porcine ventricular myocytes. Cardiovasc Res 1993;27:304-11.

17. Mukherjee R, Crawford FA, Hewett KW, Spinale FG. Cell and sarcomere contractile performance from the same cardiocyte using video microscopy. J Appl Physiol 1993; 74:2023-33.

18. Steel RGD, Torrie JH. Principles and procedures of statistics: a biometrical approach. 2nd ed. New York: McGrawHill, 1980:1-623.

19. Spinale FG, Hendrick DA, Crawford FA, Smith AC, Carabello BA. Chronic supraventricular tachycardia causes biventricular failure and subendocardial injury. Am J Physiol 1990;259:H218-29.

20. Heinsimer JA, Lefkowitz JL. The beta-adrenergic receptor in heart failure. Hosp Pract 1983; November:103-25.

21. Morkin E, Flink IL, Goldman S. Biochemical and physiologic effects of thyroid hormone on cardiac performance. Prog Cardiovasc Dis 1983;25:435-61.

22. Dudley SC, Baumgarten CM. Bursting of cardiac sodium channels after acute exposure to 3,5,3' -triiodo-L-thyronine. Circ Res 1993;73:301-13.

23. Rudinger A, Mylotte KM, Davis PJ, Davis FB, Blas SD.
Rabbit myocardial membrane $\mathrm{Ca}^{+2}$-adenosine triphosphate activity: stimulation in vitro by thyroid hormone. Arch Biochem Biophys 1984;229:379-85.

24. Chang HY, Kunos G. Short term effects of triiodothyronine on rat heart adrenoceptors. Bioch Biophys Res Commun 1981;100:313-20.

25. Hamilton MA, Stevenson LW, Luu M, Walden JA. Altered thyroid hormone metabolism in advanced heart failure. J Am Coll Cardiol 1990;16:91-5.

26. Hamilton MA, Prevalence and clinical implications of abnormal thyroid hormone metabolism in advanced heart failure. Ann Thorac Surg 1993;56:S48-53.

27. Novitzky D, Human PA, Cooper DK. Effect of triiodothyronine on myocardial high energy phosphates and lactate after ischemia and cardiopulmonary bypass. J THORAC Cardiovasc Surg 1988;96:600-7.

28. Buccino RA, Spann JF, Pool PE, Sonnenblick EH, Braunwald $E$. Influence of the thyroid state on the intrinsic contractile properties and energy stores of the myocardium. $J$ Clin Invest 1967;46:1669-82.

29. Novitzky D, Matthews N, Shawley D, Cooper DK, Zuhdi $\mathrm{N}$. Triiodothyronine in the recovery of stunned myocardium in dogs. Ann Thorac Surg 1992;51:10-7.

30. Calderone A, Bouvier M, Li K, et al. Dysfunction of the $\beta$ - and $\alpha$-adrenergic systems in a model of congestive heart failure: the pacing-overdrive dog. Circ Res 1991; 69:332-43.

31. Roth DA, Urasawa K, Helmer GA, Hammond HK. Downregulation of cardiac guanosine 5'-triphosphatebinding proteins in right atrium and left ventricle in pacing-induced congestive heart failure. J Clin Invest 1993;91:939-49.

32. Marzo KP, Frey MJ, Wilson JR, et al. $\beta$-Adrenergic receptor-G protein-adenylate cyclase complex in experimental canine congestive heart failure produced by rapid ventricular pacing. Circ Res 1991;69:1546-56.

33. Williams LT, Lefkowitz RJ, Wantanabe AM, Hathaway DR, Besch HR. Thyroid hormone regulation of $\beta$-adrenergic receptor number. J Biol Chem 1977;252:2787-89.

34. Bilezikian JP, Loeb JN, Gammon DE. The influence of hyperthyroidism and hypothyroidism on the beta-adrenergic responsiveness of the turkey erythrocyte. J Clin Invest 1979;63:184-92.

35. Spinale FG, Clayton C, Tanaka R, et al. Myocardial $\mathrm{Na}+, \mathrm{K}+$-ATPase in tachycardia induced cardiomyopathy. J Mol Cell Cardiol 1992;24:277-94. 